\title{
REBUSAN RAMBUT JAGUNG (ZEA MAYS L) EFEKTIF MENURUNKAN TEKANAN DARAH PENDERITA HIPERTENSI DI PUSKESMAS HARAPAN RAYA PEKANBARU
}

\author{
Rizka Febtrina ${ }^{1}$, Nurvaida Br. Simamora ${ }^{2}$ \\ ${ }^{1}$ Program Studi Profesi Ners, ${ }^{2}$ Program Studi Ilmu Keperawatan \\ STIKes Payung Negeri Pekanbaru Jalan Tamtama No. 06 Kel. Labuh Baru Timur Pekanbaru Indonesia \\ rizka.febtrina@payungnegeri.ac.id
}

\begin{abstract}
Abstrak
Hipertensi merupakan salah satu penyebab kematian tertinggi pada masyarakat di dunia. Penyakit ini disebut juga silent killer. Prevalensi hipertensi telah mencapai angka 31,7\% dari semua penduduk. Salah satu penatalaksanaan hipertensi dapat dilakukan secara non farmakologis. Tujuan penelitian ini adalah untuk mengetahui efektivitas rebusan rambut jagung terhadap penurunan tekanan darah pada pasien hipertensi. Penelitian ini dilaksanakan selama satu minggu dengan pemberian air rebusan rambut jagung dua kali dalam sehari yaitu pagi dan malam. Rancangan penelitian menggunakan penelitian Quasi-Eksperimen menggunakan desain pretest-posttest with control group terhadap 38 responden (19 intervensi dan 19 kontrol) yang dipilih secara purposive sampling. Hasil uji paired sample t-test pada kelompok intervensi didapatkan $p$ value 0.000 (sistolik) dan 0,000 (diastolik) (p value $<0,05$ ) yang artinya $\mathrm{H} 0$ ditolak artinya rebusan rambut jagung efektif menurunkan tekanan darah dan hasil uji paired sample t-test pada kelompok kontrol dengan nilai $p$ value 0,002 (sistolik) dan 0,001 (diastolik) (p value $<0,05$ ) sehingga $\mathrm{H} 0$ ditolak artinya pada kelompok kontrol juga terjadi penurunan tekanan darah. Sedangkan uji independent sample ttest menunjukan $p$ value 0,001 (sistolik) dan 0,000 (diastolik) ( $\mathrm{p}$ value $<0,05$ ) sehingga $\mathrm{H} 0$ ditolak. Artinya ada perbedaan tekanan darah yang bermakna antara kelompok intervensi dan kelompok kontrol. Sehingga disimpulkan bahwa rebusan rambut jagung lebih efektif menurunkan tekanan darah pada pasien hipertensi. Penelitian ini merekomendasikan agar penelitian selanjutnya dapat mengapilkasikan rebusan rambut jagung terhadap penurunan gula darah.
\end{abstract}

Kata Kunci : Hipertensi, Rambut Jagung, Tekanan darah

\begin{abstract}
Hypertension is one of the leading causes of death in people in the world. This disease is also called silent killer. The prevalence of hypertension has reached $31.7 \%$ of all population. One of the management of hypertension can be done non-pharmacologically. The purpose of this study was to determine the effectiveness of corn silk to the decrease in blood pressure in hypertensive patients. This study was conducted for one week with the provision of water boiling corn silk twice in a day that is morning and night. The research design used Quasi-Experimental research using pretest-posttest with control group design on 38 respondents (19 interventions and 19 controls) selected by purposive sampling. The results of paired sample $t$-test in the intervention group obtained $p$ value 0.000 (systolic) and 0,000 (diastolic) ( $p$ value $<0.05$ ) which means $\mathrm{H} 0$ rejected means the boiled of corn silk effectively lowers blood pressure and test results paired sample t-test in control group with $p$ value 0,002 (systolic) and 0,001 (diastolic) ( $p$ value $<0,05$ ) so that $\mathrm{H} 0$ rejected mean in control group also decrease blood pressure. The independent sample t-test shows $\mathrm{p}$ value 0.001 (systolic) and 0,000 (diastolic) ( $\mathrm{p}$ value $<0.05$ ) so that $\mathrm{H} 0$ is rejected. This means that there is a significant difference in blood pressure between the intervention group and the control group. So it is concluded that the decoction of corn silk more effectively lower blood pressure in hypertensive patients. This research recommends that further research can apply the stew of corn silk to a decrease in blood sugar.
\end{abstract}

Keywords : Hypertension, Corn silk, Blood Pressure

\section{PENDAHULUAN}

Penyakit tidak menular (PTM) merupakan penyebab utama kematian dunia, dan merupakan penyebab $68 \%$ dari 56 juta kematian pada tahun 2012 (Word Health Organization, 2014). Salah satu PTM yang 
Rizka Febtrina ${ }^{1}$, Nurvaida Br. Simamora ${ }^{2}$,Rebusan Rambut Jagung (Zea Mays L) Efektif Menurunkan Tekanan Darah Penderita Hipertensi Di Puskesmas Harapan Raya Pekanbaru

menjadi masalah kesehatan yang sangat serius saat ini adalah hipertensi. Hipertensi ditandai dengan tekanan darah sistolik (TDS) lebih dari $140 \mathrm{mmHg}$ dan atau tekanan darah diastolikik (TDD) lebih dari $90 \mathrm{mmHg}$ atau peningkatan keduanya (Tedjasukmana, 2012). Menurut WHO (2011) satu milyar orang yang terkena hipertensi, dan akan terus meningkat seiring peningkatan jumlah penduduk. Setiap tahunnya terdapat 7 juta orang diseluruh dunia meninggal akibat hipertensi (Mamahit, 2017). Peningkatan tekanan darah disebabkan oleh gaya hidup yang tidak sehat seperti mengkonsumsi makanan yang berkadar garam tinggi, makanan cepat saji, makanan yang berkolesterol, kurang berolahraga, minum alkohol, dan merokok (Palmer \& Williams, 2007).

Hasil Riset Kesehatan Dasar (Riskesdas) tahun 2013, menyebutkan prevelensi hipertensi pada penduduk umur 18 tahun keatas sebanyak 25,8\%. Prevelensi hipertensi di Indonesia diperoleh melalui kuesioner yang terdiagnosa tenaga kesehatan sebesar 9,4\%, dan yang terdiagnosa tenaga kesehatan atau minum obat sebesar $9,5 \%$ sedangkan yang minum obat sendiri sebesar $0,1 \%$. Responden yang mempunyai tekanan darah normal tetapi sedang minum obat hipertensi sebesar $0,7 \%$. Jadi, prevelensi hipertensi di Indonesia sebesar $26,5 \% \quad(25,8 \%+0,7 \%) . \quad$ Angka-angka prevelensi tersebut menunjukkan kasus hipertensi tidak terjangkau oleh layanan kesehatan. Baik dari temuan kasus (casefinding) maupun penatalaksanaan pengobatan.
Pengobatan hipertensi dapat dilakukan secara farmakologis dan non farmakologis. Pengobatan farmakologis pada hipertensi dapat dilakukan dengan pemberian obat-obatan. Sedangkan secara non farmakologi dapat menggunakan bahan - bahan alami. Pengobatan non farmakologis merupakan pelengkap terapi farmakologis untuk mendapatkan efek pengobatan yang lebih baik dan sebagai media untuk menunda pendekatan farmakologis dengan hipertensi ringan. Salah satu pengobatan non farmakologis adalah melalui terapi herbal yang memiliki bermacam-macam keuntungan bagi yang mengkonsumsinya, diantaranya harganya lebih terjangkau, mudah diperoleh, tidak menimbulkan efek samping, meningkatkan daya tahan tubuh karena mengandung banyak vitamin yang berguna bagi kesehatan. Penggunaan obat herbal alami dengan formulasi yang tepat sangat penting dan tentunya lebih aman dan efektif (Suprani \& Wulandari, 2012).

Salah satu tumbuhan yang digunakan masyarakat sebagai obat herbal yaitu rambut jagung (Nessa, Arifin, dan Muchtar, 2013). Rambut jagung mengandung senyawa antioksidan yang bermanfaat bagi tubuh. Kandungan zat aktif yang terdapat di rambut jagung adalah flavonoid. Mekanisme kerja flavoniod yaitu untuk melancarkan peredaran arah dan mencegah terjadinya penyumbatan pada pembuluh darah, sehingga darah dapat mengalir dengan normal (Margowati, 2016).

Berdasarkan data dari Dinas Kesehatan Kota Pekanbaru (2016), hipertensi masuk kedalam sepuluh besar kasus penyakit terbesar 
di Pekanbaru. Dari 20 Puskesmas di Pekanbaru, Puskesmas Harapan Raya menempati urutan kelima dengan kunjungan terbanyak sebesar 2.510 jiwa. Berdasarkan survei pendahuluan yang dilakukan dengan wawancara kepada petugas kesehatan di Puskesmas Harapan Raya bahwa pasien yang berobat atau datang adalah pasien yang menderita hipertensi yang berulang / menahun, dan ada juga pasien yang baru.

Penelitian ini bertujuan untuk mengetahui efektivitas rebusan rambut jagung (Zea mays L.) terhadap penurunan tekanan darah pada pasien hipertensi di Puskesmas Harapan Raya Pekanbaru.

\section{METODE PENELITIAN}

Penelitian ini menggunakan metode penelitian eksperimen semu (Quasieksperiment) dengan menggunakan pendekatan Pretest - Posttest with Control Grup. Teknik pengambilan sampel dengan cara Purposive sampling dengan jumlah responden sebanyak 38 penderita hipertensi esensial di wilayah kerja Puskesmas Harapan Raya Pekanbaru.

Pengukuran tekanan darah menggunakan sphygmomanometer aneroid dilakukan sebelum dan setelah pasien diberikan air rebusan rambut jagung (posttest) untuk mengetahui perubahan tekanan darah. Responden diberikan air rebusan rambut jagung sebanyak 150 gr rambut jagung dicuci setelah itu di rebus dengan 3 gelas air $(750 \mathrm{ml})$ selama 15 menit hingga tersisa 2 gelas (500 ml) dan berubah warna menjadi coklat muda, diminum $2 \times$ sehari (pagi dan malam) selama 7 hari. Data hasil pengumpulan diolah dengan menggunakan komputer dengan uji statistik $\mathrm{t}-$ test.

\section{HASIL PENELITIAN}

Karakteristik responden dalam penelitian ini dapat dilihat pada tabel 1 .

Tabel 1.

Distribusi frekuensi karakteristik responden

\begin{tabular}{|c|c|c|c|}
\hline $\begin{array}{l}\mathbf{N} \\
\mathbf{0}\end{array}$ & Variabel & $\begin{array}{l}\text { Frek } \\
\text { uensi }\end{array}$ & $\begin{array}{c}\text { Persentase } \\
(\%)\end{array}$ \\
\hline \multirow[t]{5}{*}{1} & Usia & & \\
\hline & $\begin{array}{c}\text { - Dewasa Akhir } \\
(36-45)\end{array}$ & 1 & 2.6 \\
\hline & $\begin{array}{c}\text { - Lansia awal } \\
(46-55)\end{array}$ & 26 & 68,4 \\
\hline & $\begin{array}{c}\text { - Lansia tengah } \\
(56-65)\end{array}$ & 9 & 23,7 \\
\hline & - Manula (>65) & 2 & 5,3 \\
\hline \multirow[t]{3}{*}{2} & Jenis kelamin & & \\
\hline & - Laki-laki & 15 & 39,5 \\
\hline & - Perempuan & 23 & 60,5 \\
\hline \multirow[t]{5}{*}{3} & Pendidikan & & \\
\hline & $-\mathrm{SD}$ & 17 & 44,7 \\
\hline & - SMP & 9 & 23,7 \\
\hline & - SMA & 8 & 21,1 \\
\hline & - Perguruan Tinggi & 4 & 10,5 \\
\hline \multirow[t]{5}{*}{4} & Suku & & \\
\hline & - Minang & 11 & 28,9 \\
\hline & - Batak & 7 & 18,4 \\
\hline & - Jawa & 4 & 10,5 \\
\hline & - Melayu & 16 & 42,1 \\
\hline \multirow[t]{5}{*}{5} & Pekerjaan & & \\
\hline & - IRT & 20 & 52,6 \\
\hline & - Wiraswasta & 11 & 28,9 \\
\hline & - Buruh & 5 & 13,2 \\
\hline & - Purnawirawan & 2 & 5,3 \\
\hline \multirow[t]{3}{*}{6} & Riwayat Keluarga & & \\
\hline & - Ada & 30 & 78,9 \\
\hline & - Tidak ada & 8 & 21,1 \\
\hline
\end{tabular}

Berdasarkan tabel 1 diketahui bahwa mayoritas responden berusia 45-55 tahun sebanyak 26 orang $(68,4 \%)$, sebagian besar responden berjenis kelamin perempuan sebanyak 23 orang $(60,5 \%)$, responden mayoritas pendidikan terakhir yaitu SD sebanyak 17 orang (44,7\%). dan sebanyak 16 
Rizka Febtrina ${ }^{1}$, Nurvaida Br. Simamora ${ }^{2}$,Rebusan Rambut Jagung (Zea Mays L) Efektif Menurunkan Tekanan Darah Penderita Hipertensi Di Puskesmas Harapan Raya Pekanbaru orang $(42,1 \%)$ berasal dari suku melayu. Mayoritas responden sebagai IRT sebanyak 20 orang (52,\%). Pada umumnya responden memiliki keturunan pada keluarga sebanyak 30 orang $(78.9 \%)$.

Tabel 2.

Analisis Perbedaan nilai rata-rata Tekanan Darah Pretest dan Posttest Pada Kelompok Intervensi dan kelompok kontrol pada Pasien Hipertensi di Puskesmas Harapan Raya Pekanbaru

\begin{tabular}{|c|c|c|c|c|c|}
\hline Var & Kel & Perlakuan & Mean & SD & $\begin{array}{c}\mathrm{P} \\
\text { value }\end{array}$ \\
\hline \multirow{2}{*}{ TDS } & \multirow{4}{*}{ I } & Pretest & 168,42 & 19,512 & 0,000 \\
\hline & & Posttest & 156,32 & 17,388 & \\
\hline \multirow{2}{*}{ TDD } & & Pretest & 104,21 & 5,073 & 0,000 \\
\hline & & Posttest & 90,53 & 7,050 & \\
\hline \multirow{2}{*}{ TDS } & \multirow{4}{*}{$\mathrm{K}$} & Pretest & 183,16 & 20,29 & 0,002 \\
\hline & & Posttest & 176,84 & 17,96 & \\
\hline \multirow{2}{*}{ TDD } & & Pretest & 105,26 & 6,118 & 0,001 \\
\hline & & Posttest & 100,0 & 7,454 & \\
\hline
\end{tabular}

Tabel 2 menunjukkan bahwa nilai $p$ value tekanan darah sistolik pada kelompok intervensi dan kelompok kontrol adalah 0,000 dan $0,002(<0,05)$. Hal ini dapat disimpulkan bahwa $p$ value $<0,05(<\alpha)$, sehingga Ho ditolak. Artinya, rebusan rambut jagung dan obat efektif terhadap penurunan tekanan darah sistolik pasien hipertensi. Nilai tekanan darah diastolik pada kelompok intervensi dan kelompok kontrol dengan $p$ value 0,000 dan $0,001(<0,05)$, sehingga Ho ditolak artinya rebusan rambut jagung dan obat efektif terhadap penurunan tekanan darah diastolik pada pasien hipertensi.

Tabel 3.

Analisis Perbandingan Nilai Rata-Rata Tekanan Darah antara Kelompok Intervensi dan Kelompok Kontrol Pada Pasien
Hipertensi di Puskesmas Harapan Raya Pekanbaru

\begin{tabular}{cccccc}
\hline Var & Kel & Mean & SD & $\begin{array}{c}\text { Mean } \\
\text { Diff }\end{array}$ & $\begin{array}{c}\boldsymbol{P} \\
\text { valu } \\
\boldsymbol{e}\end{array}$ \\
\hline \multirow{2}{*}{ TDS } & I & 156,32 & 17,388 & & \\
& & & & $-20,526$ & 0,001 \\
\hline \multirow{2}{*}{ K } & I & 176,84 & 17,967 & & \\
\hline & K & 100,53 & 7,050 & & \\
\hline
\end{tabular}

Berdasarkan tabel 3 hasil uji independent sample t-test diperoleh nilai $p$ value 0,001 pada TDS dan $p$ value 0,000 pada TDD. Nilai $p$ value yang diperoleh lebih kecil dari alpha $(<0,05)$ sehingga Ho ditolak, artinya ada perbedaan efektifitas sesudah pada kelompok intervensi dan kelompok kontrol dalam penurunan tekanan darah sistolik dan diastolikik pada pasien hipertensi.

\section{PEMBAHASAN}

Usia merupakan faktor kuat yang tidak dapat dimodifikasi. Arteri kehilangan elastisitas atau kelenturan seiring bertambahnya usia, dengan bertambahnya usia resiko terjadinya hipertensi meningkat. Hal ini disebabkan oleh perubahan alami pada jantung, pembuluh darah dan hormon. Apabila perubahan tersebut disertai faktor-faktor lain maka bisa memicu terjadinya hipertensi. Faktor usia merupakan faktor salah satu pencetus terjadinya hipertensi, pada lanjut usia pembuluh darah sudah kurang elastis sehingga mudah tersumbat atau pecah hal ini lah yang menyebabkan terjadinya hipertensi.

Jenis kelamin merupakan salah satu faktor yang mempengaruhi tekanan darah (Rosta, 2011). Berdasarkan hasil penelitian 
Novitaningtyas (2014), perempuan cenderung menderita hipertensi daripada laki-laki. Pada penelitian tersebut sebanyak $43,7 \%$ perempuan mengalami hipertensi, sedangkan untuk lakilaki 37,5\%. Perempuan akan mengalami peningkatan resiko tekanan darah tinggi (hipertensi) setelah menopouse yaitu usia diatas 45 tahun. Perempuan yang belum menopause dilindungi oleh hormon estrogen yang berperan dalam meningkatkan kadar High Density Lipoprotein (HDL). Kadar kolesterol HDL rendah dan tingginya kolesterol LDL (Low Density Lipoprotein) mempengaruhi terjadinya proses aterosklerosis (Anggraini dkk, 2009 dalam Novitaningtyas, 2014).

Peneliti berpendapat bahwa perempuan sangatlah beresiko terjadinya tekanan darah tinggi karena seiring bertambahnya umur perempuan juga dihubungkan dengan faktor hormonal yang lebih besar terdapat didalam tubuh perempuan dibandingkan dengan lakilaki. Faktor hormonal inilah yang menyebabkan peningkatan lemak dalam tubuh atau obesitas. Selain faktor hormonal obesitas juga terjadi karena gaya hidup yang tidak teratur seperti kurang aktivitas yang menyebabkan perempuan banyak menderita tekanan darah tinggi.

Tingkat pendidikan dapat mempengaruhi kemampuan perilaku hidup sehat, terutama mencegah kejadian hipertensi. Semakin tinggi tingkat pendidikan maka semakin tinggi pula kemamupuan seseorang dalam menjaga pola hidupnya agar tetap sehat. Hasil Riskesdas tahun 2013 dalam Badan Penelitian dan Pengembangan Kesehatan (2013) menyatakan bahwa penyakit hipertensi cenderung tinggi pada pendidikan rendah dan menurun sesuai dengan peningkatan pendidikan tingginya risiko terkena hipertensi pada pendidikan yang rendah, kemungkinan disebabkan karena kurangnya pengetahuan pada seseorang yang berpendidikan rendah terhadap kesehatan dan sulit atau lambat menerima informasi yang diberikan oleh petugas sehingga berdampak pada perilaku/pola hidup sehat.

Karakteristik suku lansia yang terkena hipertensi terjadi pada lansia yang bersuku Melayu dengan jumlah sebanyak 40 orang (46,0\%). Selain itu jumlah lansia yang bersuku Minang yang menderita hipertensi sebanyak 34 orang $(39,1 \%)$ dan lansia yang berasal dari suku Jawa sebanyak 10 orang $(11,5 \%)$ sedangkan lansia yang bersuku Batak sebanyak 3 orang $(3,4 \%)$. Hasil wawancara peneliti pada 15 orang lansia, ternyata lansia yang berasal dari suku melayu suka mengkonsumsi makanan yang bersantan dan berlemak sehingga bisa memicu terjadinya hipertensi. Hal ini sejalan dengan teori yang dinyatakan oleh Smeltzer dan Bare (2002) dalam Agustina, Sari dan Savita (2014), yakni suku atau budaya merupakan salah satu faktor resiko terjadinya hipertensi seperti mengkonsumsi makanan kegemaran.

Terdapat hubungan antara pekerjaan dengan tekanan darah tinggi, dimana wanita dan pria yang tidak bekerja atau hanya sebagai ibu rumah tangga beresiko lebih tinggi 
Rizka Febtrina ${ }^{1}$, Nurvaida Br. Simamora ${ }^{2}$,Rebusan Rambut Jagung (Zea Mays L) Efektif Menurunkan Tekanan Darah Penderita Hipertensi Di Puskesmas Harapan Raya Pekanbaru

menderita hipertensi dibandingkan dengan perempuan yang bekerja (Aisyah \& Widarti, 2011).

Faktor genetik mempengaruhi terjadinya hipertensi terdapat $85 \%$ responden yang ada riwayat keluarga dan responden yang tanpa ada riwayat sebanyak $15 \%$ (Wahyuningsih, 2013). Adanya faktor genetik pada keluarga tertentu akan menyebabkan keluarga itu mempunyai resiko menderita hipertensi. Hal ini berhubungan dengan peningkatakn kadar natrium intraseluler dan rendahnya rasio antara kalium terhadap natrium. Individu dengan riwayat orang tua hipertensi mempunyai resiko dua kali lebih besar untuk menderita hipertensi daripada orang yang tidak mempunyai keluarga dengan riwayat hipertensi dalam keluarga.

Tekanan darah adalah gaya yang diberikan darah terhadap dinding pembuluh darah dan ditimbulkan oleh desakan darah terhadap dinding arteri ketika darah tersebut dipompa dari jantung ke jaringan. Besar tekanan bervariasi tergantung pada pembuluh darah dan denyut jantung. Tekanan darah paling tinggi terjadi ketika ventrikel berkontraksi (takanan sistolik) dan paling rendah ketika ventrikel berelaksasi (tekanan diastolik). Pada keadaan hipertensi, tekanan darah dipompakan melalui pembuluh darah dengan kekuatan berlebih (Nuraini, 2015).

Berbagai penelitian menyebukan bahwa penyebab hipertensi terjadi akibat obesitas, tinggi konsumsi garam, gaya hidup yang tidak sehat, stres, dan kurangnya konsumsi potasium dan kalsium pada beberapa kasus. Sehingga diperlukan berbagai upaya untuk menurunkan tekanan darah. Salah satu yang bisa dilakukan adalah dengan stimulus kadar potassium dan kalium.

Peranan rebusan rambut jagung terhadap penurunan tekanan darah pada pasien hipertensi terjadi karena adanya kandungan flavonoid yang dapat menurunkan tekanan darah dengan cara pembentukan oksida nitrat menyebabkan dinding pembuluh darah menjadi rileks yang berasal dari L-arginin oksigen dari berbagai enzin nitrogen oksida sintase, endothelium (lapisan dalam) pembuluh darah menggunakan oksida nitrat untuk sinyal otot polos sekitarnya untuk relaksasi, sehingga mengakibatkan vasodilatasi dan meningkatkan aliran darah menjadi terbuka lebih luas. Hal ini berarti cara kerja terapi mengkonsumsi rebusan rambut jagung sama halnya dengan obat-obatan antihipertensi golongan diuretic dalam menurunkan tekanan darah (Puradisastra, 2010).

Kandungan yang juga terdapat dalam rambut jagung yaitu kalium, kalsium dan natrium. Kalium berfungsi dalam memelihara keseimbangan cairan, elektrolit dan asam basa. Mekanisme kalium dapat menurunkan tekanan darah adalah dengan cara vasodilatasi sehingga menyebabkan penurunan retensi perifer total dan meningkatkan output jantung, kalium dapat menurunkan tekanan darah dengan berkhasiat sebagai diuretic, kalium dapat mengubah aktivitas sistem reninangiotensin, kalium dapat mengatur saraf 
perifer dan sentral yang mempengaruhi tekanan darah. Kalium (potassium) merupakan ion utama didalam cairan intraseluler.

Interaksi ini lah yang menyebabkan penurunan tekanan darah, sehingga rebusan rambut jagung efektif untuk penurunkan tekanan pada pasien hipertensi.

\section{SIMPULAN}

Penelitian ini dapat disimpulkan bahwa rebusan rambut jagung lebih efektif dalam menurunkan tekanan darah pada pasien hipertensi. Hal ini dikarenakan rambut jagung memiliki kandungan yang dapat merilekskan pembuluh darah dan terjadi peningkatan aliran darah yang menyebabkan penurunan tekanan darah pada pasien hipertensi.

\section{SARAN}

Hasil penelitan ini diharapkan dapat menjadi bahan alternatif untuk pengobatan herbal dalam menurunkan tekanan darah tinggi dan dapat dijadikan acuan untuk penelitian selanjutnya dengan mengaplikasikan manfaat rambut jagung pada penyakit lain seperti menurunkan gula darah, kolesterol dll.

\section{DAFTAR PUSTAKA}

Aisyah Ayu F., \& Widarti. (2011). Analisis Faktor-faktor yang Mempengaruhi Kejadian Hipertensi Primer di Desa Trunuh Klaten Selatan. Naskah Publikasi : Aisyiya Yogyakarta

Agustina S., Sari M.,S., \& Savita R. (2014). Faktor-Faktor yang Berhubungan dengan Hipertensi Pada Lansia di Atas Umur 65 Tahun. Jurnal Kesehatan Komunitas, Vol. 2, No. 4.

Anggara1 F., H., D., \& Prayitno N., 1. (2013). Faktor-Faktor yang Berhubungan dengan
Tekanan Darah di Puskesmas Telaga Murni, Cikarang Barat Tahun 2012. Jurnal Ilmiah Kesehatan, 5(1); Jan 2013.

Bangun. A. P. (2008). Khasiat Tanaman Obat untuk Hipertensi.. Jakarta : Indocamp.

Black, J. M \& Hawks, J. H. (2014). Keperawatan Medikal Bedah .Edisi 8. Singapura : Elsevier.

Dalimartha, Setiawan. (2008). Atlas Tumbuhan Obat Indonesia. Jakarta: Trubus Agriwidya.

Dewi, S., Familia, D. (2010). Hidup Bahagia Dengan Hipertensi. Yogyakarta: Plus Books.

Dharma, Kelana K. (2011). Metodologi Penelitian (Pedoman Melaksanakan dan Menerapkan Hasil Penelitian). Jakarta : TIM.

Dinas Kesehatan Kota Pekanbaryu. (2016). Profil Kesehatan Kota Pekanbaru. Pekanbaru: Kepala Dinas Kota Pekanbaru.

Elsanti, Salma. (2009). Panduan Hidup Sehat Bebas Kolesterol, Stroke, Hipertensi \& Serangan Jantung. Yogyakarta: Araska.

George, G., Idu, F., Obika, L. (2013). Effects of corn silk aqueous extract on intraocular pressure of ocular hypertensive human subjects. The South African Optometrist. 72(3) 133-143.

Herman, H., Putra, B . (2015). Uji Antihipertensi Infus Kombinasi Biji dan Rambut Jagung (Zea Mays L.) pada Tikus Jantan (Rattus Norvegicus) dengan Metode Tail Cuff Non Invasive. Jurnal Media Farmasi Vol 12, N. 1, P 93-103.

Hidayat, A. Aziz Alimul. (2009). Metode Penelitian Keperawatan dan Teknik Analisa Data. Jakarta ; Salemba Medika.

Indriyani, W. nur. (2009). Deteksi Dini Kolesterol, Hipertensi \& Stroke. Yogyakarta: Milestone.

Ismiati, E. retno. (2015). Aktivitas Antioksidan Minuman Herbal Rambut Jagung dengan Variasi Kondisi dan Lama Perebusan. Skripsi Program Studi Pendidikan Biologi. Surakarta: Universitas Muhammadiyah Surakarta.

Kholish, N. (2011). Bebas Hipertensi Seumur Hidup dengan Terapi Herbal. Yogyakrta: Real Books.

Mamahit, M., Mulyadi, \& Onibala, F . (2017). Hubungan Pengetahuan Tentang Diet Garam dengan Tekanan Darah Pada Lansia di Puskesmas Bahu Kota Manado. e-journal keperawatan Vol: 5 Nomor 1.XMartha, Karnia. (2012). Panduan Cerdas Mengatasi Hipertensi. Yogyakarta: Araska.

Margowati, S., Priyanto, S., Wiharyani, M., Kesehatan, F., \& Magelang, U. M. (2016). Efektivitas Pengunaan Rebusan Daun Alpukat Dengan Rebusan Daun Salam Dalam Penurunan Tekanan Darah Pada Lansia. Universty Research Coloquium, 234-248. 
Rizka Febtrina ${ }^{1}$, Nurvaida Br. Simamora ${ }^{2}$,Rebusan Rambut Jagung (Zea Mays L) Efektif Menurunkan Tekanan Darah Penderita Hipertensi Di Puskesmas Harapan Raya Pekanbaru

Nessa, Arifin, H., \& Muchtar, H. (2013) . Efek Diuretik dan Daya Larut Batu Ginjal dari Ekstrak Rambut Jagung (Zea Mays L.). Universitas Andalas. Prosiding Seminar Nasional Perkembangan Terkini Sains Farmasi dan Klinik III, 345-358.

Nuraini, B. (2015) . Risk Factors of Hypertension.. J MAJORITY. Vol ume 4 Nomor 5, P 1019.

Nuridayanti, E. (2011). Uji Toksisitas Akut Ekstrak Air Rambut Jagung (Zea mays L.) Ditinjau dari Nilai LD50 dan Pengaruhnya Terhadap Fungsi Hati dan Ginjal Pada Mancit. Universitas Indonesia.

Nursalam.(2013). Metodologi Penelitian Ilmu Keperawatan edisi 3.Jakarta : Salemba Medika.

Notoatmodjo, S. (2012). Metodologi Penelitian Kesehatan. Jakarta : Rineka Cipta

Novitaningtyas .,T. (2014). Hubungan Karakteristik (Umur, Jenis Kelamin, Tingkat Pendidikan) dan Aktivitas Fisik Dengan Tekanan Darah Pada Lansia di Kelurahan Makamhaji Kecamatan Kartasura Kabupaten Sukoharjo. Naskah Publikasi. Universitas Muhammadiyah Surakarta.

Palmer, A., \& Williams, B. (2007). Simple Guides Tekanan Darah Tinggi. Jakarta: Erlangga.

Prasiddha, I., J., Laeliocattleya, R., A Estiasih, T. (2016) . Potensi Senyawa Bioaktif Rambut Jagung Untuk Tabir Surya Alami . Jurnal Pangan dan Agroindustri Vol. 4 No 1 P. 4045.

Perry, A. G \& Potter, P. A (2009). Fundamental Keperawatan. Edisi 7, buku 2. Jakarta : Salemba Medika.

Puradisastra, S. (2010). The Effect Of Corn Cob and Corn Silk ( Zea Mays l.) Decoction On The Blood Pressure on Adult Female. Jurnal Medika Planta. Vol 1, No. 2.

Ramadani, F.,H,. Intannia, D,. Ni, M. (2016). Profil Penurunan Kadar Glukosa Darah Ekstrak Air Rambut Jagung (Zea Mays L.) Tua dan Muda Pada Mencit Jantan Galur Balb-C. Jurnal Pharmascience, Vol 3, No. 1, hal: 37 - 44.

Ridwan, M. (2009). Mengenal, Mencegah, Mengatasi Silent Killer Hipertensi. Semarang: KDT.

Riskesdas. (2013) . Badan Penelitian dan Pengembangan Kesehatan Republik Indonesia. Jakarta: Kepala Badan Penelitian dan Pengembangan Kesehatan Republik Indonesia.

Smeltzer \& Bare. (2002). Keperawatan Medikal Bedah Ed 8. Jakarta: EGC.

Suparni, Ibunda \& Wulandari, Ari.( 2012) . Herbal
Nusantara : 1001 Ramuan Tradisional Asli Indonesia. Yogyakarta: Rapha Publishing.

Susilo, Y., \& Wulandari, A. (2011) . Cara Jitu Mengatasi Hipertensi. Yogyakarta: Andi.

Sutanto. (2010) . Cekal (Cegah \&Tangkal) Penyakit Modern (Hipertensi, Stroke,

Jantung, Kolesterol, dan Diabetes). Yogyakarta: CV Andi Offset.

Tedjasukmana, P. (2012). Tata Laksana Hipertensi.Cdk, 39(4), 251-255. Jakarta: Jurnal Kedokteran Indonesia.

Wahyuningsih, Endri Astuti. (2013) . Faktor Yang Mempengaruhi Hipertensi pada Usia Lanjut. Jurnal Ners dan Kebidanan Indonesia. ISSN2354-7642.

Wijayanti, F., Ramadhian, M. (2016). Efek Rambut Jagung (Zea Mays L.) Terhadap Penurunan Kadar Kolesterol dalam Darah. J Majority. Volume 5, P 91-95. 